\title{
Association between diarrhea quantity and in- hospital mortality in intensive care unit patients: A retrospective cohort study
}

\section{Ryohei Yamamoto}

Kyoto University Graduate School of Medicine Faculty of Medicine: Kyoto Daigaku Daigakuin Igaku Kenkyuka Igakubu https://orcid.org/0000-0002-5144-6585

Hajime Yamazaki

Kyoto University: Kyoto Daigaku

Shungo Yamamoto

Kyoto University: Kyoto Daigaku

\section{Yuna Ueta}

Kameda Medical Center

\section{Ryo Ueno}

Australian and New Zealand intensive care research center

Yosuke Yamamoto ( $\triangle$ yamamoto.yosuke.5n@kyoto-u.ac.jp )

Australian and New Zealand intensive care research center https://orcid.org/0000-0003-1104-2612

\section{Research}

Keywords: intensive care, diarrhea, mortality, retrospective cohort study

Posted Date: September 2nd, 2021

DOl: https://doi.org/10.21203/rs.3.rs-859799/v1

License: (9) This work is licensed under a Creative Commons Attribution 4.0 International License. Read Full License 


\section{Abstract \\ Background}

Previous studies have shown that diarrhea is associated with increased mortality of patients in intensive care units (ICUs). However, these studies used dichotomized cutoff values, even if diarrhea was a continuous condition. This study aimed to assess the association between diarrhea quantity and mortality in ICU patients with newly developed diarrhea.

\section{Methods}

We conducted this single-center retrospective cohort study at the Kameda Medical Center ICU. We consecutively included all adult ICU patients with newly developed diarrhea in the ICU between January 2017 and December 2018. Newly developed diarrhea was defined based on a Bristol stool chart scale $\geq 6$ and frequency of diarrhea $\geq 3$ times per day. We excluded patients who already had diarrhea on the day of ICU admission among other criteria. We collected data on the quantity of diarrhea on the day when patients newly developed diarrhea. The primary outcome was in-hospital mortality. The risk ratio (RR) and 95\% confidence interval ( $\mathrm{Cl}$ ) for the association between the quantity of diarrhea and mortality were estimated using multivariable-modified Poisson regression models adjusted for the Charlson Comorbidity Index, sequential organ failure assessment score, and serum albumin levels.

\section{Results}

Among 231 participants, $68.4 \%$ (158/231) were men; the median age of the patients was 72 years. The median quantity of diarrhea was $401 \mathrm{~g}$ (interquartile range [IQR] 230-645 g), and in-hospital mortality was $22.9 \%$ (53/231). More diarrhea at baseline was associated with higher in-hospital mortality; the unadjusted RR $(95 \% \mathrm{Cl})$ per 200-g increase was 1.10 (1.01-1.19). This association remained in the multivariable-adjusted analysis; the adjusted RR (95\% Cl) per 200-g increase was $1.10(1.01-1.20)$.

\section{Conclusions}

A greater quantity of diarrhea was an independent risk factor for in-hospital mortality. The quantity of diarrhea may be an indicator of disease severity in ICU patients.

\section{Background}

Diarrhea is a common gastrointestinal symptom in the intensive care unit (ICU), with an incidence of 1078\% [1]. In ICU patients, enteral nutrition (composition, osmolarity, speed, intermittent or continuous, fiber), drugs (e.g., antibiotics, laxatives), infectious diseases (e.g., Clostridium difficile infection [CDI]), and comorbidity (e.g., anemia, cirrhosis) are common causes of diarrhea [2]. The effects of diarrhea include 
increased risk of contamination of devices and wounds, dehydration, electrolyte abnormalities, and malabsorption [3-5].

Several studies have shown an association between diarrhea and mortality [6-14], and this association remained even in ICU patients without CDI [8]. Taito et al. conducted a systematic review and demonstrated that diarrhea was associated with the length of hospital stay and ICU mortality [14]; however, all previous studies defined diarrhea based on dichotomized criteria with respect to consistency and frequency. The European Society of Intensive Care Medicine (ESICM) has adopted dichotomized criteria for the quantity of diarrhea as a component of the definition of diarrhea in the ICU [3]. However, healthcare providers need to make decisions based on continuous conditions rather than dichotomized conditions in practice $[15,16]$. For example, more diarrhea may cause worse electrolyte imbalance, nutritional deficit, and hemodynamic instability owing to water loss $[17,18]$, which leads to changes in clinical management. Moreover, more diarrhea may result in more deaths. To clarify this, it is necessary to quantify the relationship between the quantity of diarrhea and death.

This retrospective cohort study aimed to investigate the association between the quantity of diarrhea and mortality in ICU patients with newly developed diarrhea.

\section{Methods}

\section{Study design and setting}

We conducted this single-center retrospective cohort study at Kameda Medical Center ICU. This study was reviewed and approved by the institutional review board of Kameda Medical Center and Kyoto University. These committees waived the requirement of informed consent from all participants enrolled in this study because of the retrospective study design. This study was conducted according to the Strengthening the Reporting of Observational Studies in Epidemiology (STROBE) guidelines [19].

\section{Study population}

From January 2017 to December 2018, we consecutively included all patients aged $\geq 18$ years with newly developed diarrhea in the ICU. We defined newly developed diarrhea in the ICU as three or more loose or liquid stools per day according to the World Health Organization (WHO) definition [20]. To include patients with newly developed diarrhea in the ICU, the following patients were excluded on the day of ICU admission: patients with a stoma, chronic diarrhea (e.g., inflammatory bowel syndrome, short bowel syndrome), post-gastrointestinal surgery, gastrointestinal bleeding, or bacterial and viral enteritis (including Clostridium difficile enteritis and cytomegalovirus enteritis) or those who already had diarrhea on the day of ICU admission. In addition, patients readmitted to the ICU and those who died on the day of admission were excluded.

\section{Data collection}


We collected data such as age, sex, admission category (medical or surgery), sepsis defined by sepsis-3 [21], ICU readmission, Charlson Comorbidity Index (CCI) [22], and treatment limitation (limitations in providing ICU-specific life-sustaining therapies such as mechanical ventilation, cardiopulmonary resuscitation) from electronic health record reviews. Other data such as Acute Physiology and Chronic Health Evaluation (APACHE) II score [23], Simplified Acute Physiology Score (SAPS) II [24], Sequential Organ Failure Assessment (SOFA) score [25], potential causes of diarrhea (proton pump inhibitor, enteral nutrition, antibiotics, laxative drugs), testing for CDI (glutamate dehydrogenase test, CD toxin, or stool culture), and biopsy-diagnosed cytomegalovirus enteritis were also collected. We refer to $\mathrm{CCl}$ with age score as "CCl" and defined $\mathrm{CCl}$ without age score as "CCl without age score."

\section{Measurement of diarrhea}

Stool data of ICU patients were collected from electronic health records. Nurses routinely checked the presence or absence of stools every 2-4 h. If there was a stool, consistency and quantity were assessed. Each stool sample was evaluated using the Bristol Stool Chart Scale (BSCS) [26]. The BSCS is a 7-point scale in which stools are scored according to cohesion and surface cracking as follows: 1 . separate hard lumps like nuts; 2 . sausage shaped but lumpy; 3 . like a sausage or snake but with cracks on its surface; 4 . like a sausage or snake and smooth and soft; 5 . soft blobs with a clear-cut edge; 6 . fluffy pieces with ragged edges and mushy; and 7. watery with no solid pieces. A BSCS of 6 or 7 is classified as diarrhea $[27,28]$. This scale has been evaluated for its concordance and is a widely used scale [28-34]. The quantity of stool was measured using a weight scale and recorded in the electronic medical records. Since most ICU patients had urinary catheters, contamination of the stool by urine was minimized. The main exposure was the quantity of diarrhea per day on the day of the diarrhea diagnosis. The daily quantity of diarrhea was calculated from calendar days (total quantity from 0:00 to 24:00). These data were collected from the electronic health records.

\section{Outcome measurement}

The primary outcome was in-hospital mortality. Secondary outcomes included ICU, 28-day, and 90-day mortalities; ICU-free days at the 28th day [35]; and hospital-free days at the 90th day [36]. In these free days, we used the event-free survival day (the number of event-free days was considered to be zero for patients who died in the time frame) to measure these outcomes [33, 34, 38].

\section{Statistical analyses}

Patient characteristics are described as median and interquartile range (IQR). Modified Poisson regression models were used to estimate risk ratios (RRs) and $95 \%$ confidence intervals (Cls) for the association between the quantity of diarrhea (per 200-g increase) and in-hospital mortality [37, 38]. The reason for using the unit of $200 \mathrm{~g}$ is that the ESICM definition of diarrhea is $200-250 \mathrm{~g}$ [3]. The multivariable analysis was adjusted for $\mathrm{CCl}$, SOFA score, and serum albumin levels. These covariates were selected a priori based on clinical plausibility and previous studies $[2,8,13]$. We performed multiple imputations for missing values using multiple imputations by chained equation (MICE) with 50 iterations that generated 100 datasets with imputed missing values $[39,40]$. 
To perform sensitivity analyses, we tested several modified Poisson regression models to assess the robustness of the primary analysis. First, we adjusted for the following covariates: model 1 for age, sex, $\mathrm{CCl}$ without age score, SOFA score, and serum albumin; model 2 for $\mathrm{CCl}$, APACHE II score, and serum albumin; model 3 for CCl, SAPS II score, and serum albumin; and model 4 for $\mathrm{CCl}$, SOFA score, serum albumin, and enteral nutrition. Second, we conducted a complete case analysis. Third, because CDI and cytomegalovirus enteritis affect mortality, we performed a further analysis excluding patients diagnosed with them after ICU admission. Finally, instead of using continuous data (the actual quantity of diarrhea), we used categorical data (near quartiles of the quantity of diarrhea) for the primary model.

We applied the same analyses as that for the primary outcome to assess the association between the quantity of diarrhea (per 200-g increase) and the following secondary outcomes: ICU mortality, 28-day mortality, and 90-day mortality.

We reported $95 \%$ Cls as an informal measure of uncertainty and avoided using terms such as statistical significance according to the recommendation of the American Statistical Association [41]. The analyses were performed using R software, version 4.0.3 (The R Foundation for Statistical Computing, Vienna, Austria; https://www.R-project.org/).

\section{Results}

\section{Patient characteristics}

During the study period, 1579 adult patients were admitted to the ICU, and 334 patients with newly developed diarrhea were included in this study. Among those patients, 103 were excluded. Finally, 231 patients were included in the analysis (Fig. 1).

The median age of patients was 72 (IQR [64, 80]) years, 158/231 (68.4\%) patients were men, median CCI was two (IQR [1, 3]), median APACHE II score was 21 (IQR [14, 28]), and median SOFA score was 9 (IQR [6, 12]). Patients admitted for nonoperative reasons were the most prevalent $(162 / 231,70.1 \%)$. Sepsis was diagnosed in 121 patients (52.4\%). Antimicrobials and laxative drugs as possible causes of diarrhea were administered to 214/231 (92.6\%) and 119/231 (51.5\%) patients, respectively. Overall, 2/231 (0.9\%) patients were diagnosed with $\mathrm{CDI}$ in the ICU, and two $(0.9 \%)$ patients were diagnosed with $\mathrm{CMV}$ by colonoscopic biopsy in the ICU. The medina number of days from ICU admission to newly developed diarrhea was $3($ IQR $[2,6])$, and the median quantity of diarrhea was 401 (IQR [230.5, 645]) g. Other patient characteristics on ICU admission are summarized in Table 1. Three patients had missing values for the severity score because arterial blood gas was not measured. There were no missing measurements for other variables, including the quantity of diarrhea. 
Table 1

Baseline characteristics of the study patients

Total $\mathbf{n}=\mathbf{2 3 1}$

Sex, males, n (\%)

Age, median [IQR]

Admission source, $\mathrm{n}(\%)$

Hospital ward

Emergency department

Elective surgery

Emergency surgery

Charlson comorbidity index, median [IQR]

Serum albumin, median [IQR], g/dL

SOFA score*, median [IQR]

APACHE II score*, median [IQR]

SAPS II score*, median [IQR]

ARDS, n (\%)

Sepsis, n (\%)

Acute kidney injury, n (\%)

Renal replacement therapy, n (\%)

Mechanical ventilation, $\mathrm{n}(\%)$

Noradrenaline, $\mathrm{n}(\%)$

Proton pump inhibitor, $\mathrm{n}(\%)$

Laxative drug, n (\%)

Antibiotics, n (\%)

Antiviral, n (\%)

Chemotherapy, n (\%)

Enteral nutrition, $\mathrm{n}(\%)$

Clostridium difficile infection ${ }^{\dagger}, \mathrm{n}(\%)$

Cytomegalovirus enteritis, $\mathrm{n}(\%)$
$158(68.4)$

$72[64,80]$

$56(24.2)$

$106(45.9)$

39 (16.9)

30 (13.0)

$2[1,3]$

$2.80[2.20,3.20]$

$9[6,12]$

$21[14,28]$

$48[37,60]$

42 (18.2)

121 (52.4)

105 (41.1)

$58(25.1)$

$147(63.6)$

$139(60.2)$

$196(84.8)$

119 (51.5)

$214(92.6)$

18 (7.8)

8 (3.5)

157 (68.0)

2 (0.9)

$2(0.9)$ 


\begin{tabular}{|c|c|}
\hline & Total $n=231$ \\
\hline Quantity of diarrhea, median [IQR], g & $401[230,645]$ \\
\hline Onset of diarrhea ${ }^{\ddagger}$, median [IQR], day & $3[2,6]$ \\
\hline $\begin{array}{l}\text { *Three missing data } \\
\text { †Defined by glutamate dehydrogenas } \\
\ddagger \text { Number of days from ICU admission }\end{array}$ & toxin positivity. \\
\hline $\begin{array}{l}\text { IQR: Interquartile range, SOFA: Seque } \\
\text { distress syndrome, APACHE II: Acute } \\
\text { SAPS II Simnlified acute phvsioloav }\end{array}$ & $\begin{array}{l}\text { ARDS: Acute respiratory } \\
\text { ase Classification System, }\end{array}$ \\
\hline
\end{tabular}

\section{Association between the quantity of diarrhea and outcomes}

Table 2 presents the primary and secondary outcomes. Two and 16 patients were lost to 28-day and 90day follow-ups, respectively. In the unadjusted analysis, the quantity of diarrhea was associated with increased in-hospital mortality (unadjusted RR per 200 g increased: 1.10 [95\% Cl 1.01-1.19], p = 0.03). After adjusting for $\mathrm{CCl}$, SOFA score, and serum albumin level, this association remained (adjusted RR per 200-g increase: 1.10 [95\% Cl 1.01-1.20], $p=0.03$ ) (Table 3).

Table 2

Summary of primary and secondary outcomes

\begin{tabular}{|c|c|}
\hline & Total $n=231$ \\
\hline \multicolumn{2}{|l|}{ Primary outcome } \\
\hline Hospital mortality, n/total n (\%) & $53 / 231(22.9)$ \\
\hline \multicolumn{2}{|l|}{ Secondary outcomes } \\
\hline ICU mortality, n/total n (\%) & 21/231 (9.1) \\
\hline 28-day mortality*, n/total n (\%) & $35 / 229(15.3)$ \\
\hline 90-day mortality ${ }^{\dagger}, \mathrm{n} /$ total $\mathrm{n}(\%)$ & $52 / 215(24.2)$ \\
\hline ICU LOS, median [IQR], day & $7.0[4.0,12.4]$ \\
\hline ICU-free day survival at $28^{\star}$, median [IQR], day & $20.0[14.0,23.0]$ \\
\hline Hospital LOS, median [IQR], day & $35.0[18.4,58.0]$ \\
\hline Hospital-free day survival at $90^{\dagger}$, median [IQR], day & $45.0[0,66.5]$ \\
\hline \multicolumn{2}{|c|}{$\begin{array}{l}\text { *Two patients lost to follow-up, }+16 \text { patients lost to follow-up. There were no missing measurement } \\
\text { in other outcomes. IQR: Interquartile range, LOS: Length of stay, IQR: Interquartile range, LOS: Length } \\
\text { of stay }\end{array}$} \\
\hline
\end{tabular}


Table 3

Association between the quantity of diarrhea and in-hospital mortality

\begin{tabular}{|c|c|c|c|c|}
\hline & \multicolumn{2}{|l|}{ Unadjusted } & \multicolumn{2}{|l|}{ Adjusted } \\
\hline & $\operatorname{RR}[95 \% \mathrm{Cl}]$ & $\begin{array}{l}\mathrm{p}- \\
\text { value }\end{array}$ & $\mathrm{RR}[95 \% \mathrm{Cl}]$ & $\begin{array}{l}\mathrm{p}- \\
\text { value }\end{array}$ \\
\hline $\begin{array}{l}\text { Primary analysis (per } 200-\mathrm{g} \text { diarrhea } \\
\text { increase) }\end{array}$ & $\begin{array}{l}1.10[1.01 \\
1.19]\end{array}$ & 0.031 & $\begin{array}{l}1.10[1.01 \\
1.20]\end{array}$ & 0.029 \\
\hline \multicolumn{5}{|l|}{$\begin{array}{l}\text { Sensitivity analyses (per } 200 \text {-g diarrhea } \\
\text { increase) }\end{array}$} \\
\hline Model 1 & & & $\begin{array}{l}1.09[0.98 \\
1.20]\end{array}$ & 0.080 \\
\hline Model 2 & & & $\begin{array}{l}1.10[1.01 \\
1.20]\end{array}$ & 0.028 \\
\hline Model 3 & & & $\begin{array}{l}1.11[1.02 \\
1.22]\end{array}$ & 0.018 \\
\hline Model 4 & & & $\begin{array}{l}1.10[1.00 \\
1.20]\end{array}$ & 0.041 \\
\hline Complete case analysis & $\begin{array}{l}1.10[1.05 \\
1.15]\end{array}$ & $0.001>$ & $\begin{array}{l}1.10[1.04 \\
1.17]\end{array}$ & 0.002 \\
\hline Exclude CDI or CMV diagnosed in ICU & $\begin{array}{l}1.10[1.03, \\
1.17]\end{array}$ & 0.006 & $\begin{array}{l}1.14[1.04 \\
1.24]\end{array}$ & 0.004 \\
\hline \multicolumn{5}{|l|}{ Quantile-defined categories } \\
\hline Mild $(<250 \mathrm{~g})$ & $\begin{array}{l}1.00 \\
\text { (reference) }\end{array}$ & & $\begin{array}{l}1.00 \\
\text { (reference) }\end{array}$ & \\
\hline Moderate $(250-399 \mathrm{~g})$ & $\begin{array}{l}0.97[0.38 \\
2.49]\end{array}$ & 0.953 & $\begin{array}{l}1.02[0.51 \\
2.04]\end{array}$ & 0.963 \\
\hline Severe $(400-649 \mathrm{~g})$ & $\begin{array}{l}1.11[0.46 \\
2.68]\end{array}$ & 0.823 & $\begin{array}{l}1.29[0.69 \\
2.43]\end{array}$ & 0.421 \\
\hline Very severe $(\geq 650 \mathrm{~g})$ & $\begin{array}{l}1.61[0.85 \\
3.04]\end{array}$ & 0.145 & $\begin{array}{l}1.77[0.99 \\
3.21]\end{array}$ & 0.056 \\
\hline \multicolumn{5}{|c|}{$\begin{array}{l}\text { Primary model: CCI, SOFA score, and serum albumin, Model 1: age, sex, } \mathrm{CCl} \text { without age score, SOFA } \\
\text { score, and serum albumin. Model 2: CCl, APACHE II score, and serum albumin. Model } 3: \text { CCI, SAPS II } \\
\text { score, and serum albumin. Model 4: CCI, SOFA score, serum albumin, and enteral nutrition }\end{array}$} \\
\hline $\begin{array}{l}\text { RR: Risk ratio, Cl: Confidence interval, } \\
\text { Failure Assessment, CDI: Clostridium }\end{array}$ & $\begin{array}{l}\text { on comorbid } \\
\text { ection, CMV: }\end{array}$ & $\begin{array}{l}\text { dex, SOF } \\
\text { negalovi }\end{array}$ & $\begin{array}{l}\text { : Sequential } \\
\text { is enteritis }\end{array}$ & \\
\hline
\end{tabular}

\section{Sensitivity analyses for the primary analysis}


The association between the quantity of diarrhea and in-hospital mortality remained similar in various multivariable analysis models and other sensitivity analyses (Table 3). We also performed a sensitivity analysis using the categories of the quantity of diarrhea. With no established criteria to distinguish the quantity of diarrhea, we used near-quantile-defined categories of the quantity of diarrhea. The quartiles of diarrhea were $230 \mathrm{~g}$ in the 25th percentile, $401 \mathrm{~g}$ in the 50th percentile, and $645 \mathrm{~g}$ in the 75th percentile. Therefore, the patients were divided into the following categories: mild ( $<250 \mathrm{~g})$, moderate $(250-399 \mathrm{~g})$, severe (400-649 g), and very severe ( $\geq 650 \mathrm{~g})$. In-hospital mortality was $19.7 \%$ (12/61) for mild, $19.2 \%$ (10/52) for moderate, $21.3 \%$ (13/61) for severe, and 31.6\% (18/57) for very severe. Multivariable-modified Poisson regression analysis using these categories, with the same adjustments as in the primary model, showed a trend toward increased in-hospital mortality as the quantity of diarrhea increased (Table 3).

\section{Secondary analyses}

For secondary analyses, a similar association was observed between the quantity of diarrhea and ICU 28day and 90-day mortalities (Table 4). Multivariable analysis showed a similar trend of higher mortality with higher quantities of diarrhea.

Table 4

Association between 200-g increase in the quantity of diarrhea and secondary outcomes

\begin{tabular}{|c|c|c|c|c|}
\hline & \multicolumn{2}{|l|}{ Unadjusted } & \multicolumn{2}{|l|}{ Adjusted } \\
\hline & $\mathrm{RR}[95 \% \mathrm{Cl}]$ & p-value & $\mathrm{RR}[95 \% \mathrm{Cl}]$ & p-value \\
\hline ICU mortality & $1.17[1.07,1.29]$ & 0.001 & $1.20[1.07,1.35]$ & 0.002 \\
\hline 28-day mortality & $1.11[1.01,1.23]$ & 0.028 & $1.11[0.99,1.23]$ & 0.053 \\
\hline 90-day mortality & $1.10[1.01,1.19]$ & 0.028 & $1.11[1.01,1.21]$ & 0.025 \\
\hline \multicolumn{5}{|c|}{ All analyses were adjusted for $\mathrm{CCl}$, SOFA score, and serum albumin level. } \\
\hline \multicolumn{5}{|c|}{$\begin{array}{l}\text { RR: Risk ratio, Cl: Confidence interval, CCl: Charlson comorbidity index, SOFA: Sequential Organ } \\
\text { Failure Assessment }\end{array}$} \\
\hline
\end{tabular}

\section{Discussion}

In this retrospective study, we investigated the association between the quantity of diarrhea and inhospital mortality in 231 patients with newly developed diarrhea in the ICU. Multivariable analysis revealed that diarrhea quantity was an independent predictor of in-hospital mortality. This association was consistent across several sensitivity analyses. Similarly, the greater the quantity of diarrhea, the higher the ICU 28-day and 90-day mortalities. To the best of our knowledge, this is the first study to show an association between the quantity of diarrhea and mortality.

Previous studies have reported an association between the presence of diarrhea and mortality; however, no studies have examined whether mortality increases with a greater quantity of diarrhea [14, 42]. A systematic review of 12 studies, most of which used the definition of diarrhea as three or more loose or 
liquid stools, showed an association between diarrhea and mortality (RR: $1.43 ; 95 \% \mathrm{Cl}: 1.03-1.98 ; \mathrm{I}^{2}=$ $86.7 \% ; n=11,866$ ) [14]. We focused on the quantity of diarrhea in this study and showed that mortality increased with increasing quantity of diarrhea according to the adjusted RR in patients with newly developed diarrhea in the ICU. More diarrhea leads to worse electrolyte imbalance, nutritional deficit, and hemodynamic instability owing to water loss $[17,18]$. Clinicians need to correct electrolytes, adjust enteral nutrition, and increase fluid administration as diarrhea increases.

The reason for the higher mortality rate among patients with a greater quantity of diarrhea remains unclear. Patients with CDI or cytomegalovirus enteritis, which are common diseases causing diarrhea, have been reported to have higher mortality, but they were excluded from our study. Indeed, diarrhea can cause dehydration, electrolyte abnormalities, metabolic acidosis, malnutrition, device contamination, and wound contamination [1]. However, since dehydration and electrolyte abnormalities are carefully corrected in the ICU, it is questionable to assume that diarrhea directly contributes to mortality.

Possible explanations for the relationship between diarrhea and mortality are as follows. First, diarrhea can be a sign of gastrointestinal organ failure that is associated with a high risk of mortality $[4,14,43]$. Patients with diarrhea have higher severity scores than those without diarrhea $[2,6,8-10,14]$. In our study, most patients received treatments that could cause diarrhea, such as enteral nutrition and antimicrobials. These interventions are part of the treatment regimen for critically ill patients. In addition, approximately $60 \%$ of patients were on ventilation and used vasopressors, which means that patients with diarrhea have a higher severity of illness. In our analysis, we adjusted for the SOFA score, an organ disorder score that does not include gastrointestinal function and showed that diarrhea is a risk factor for mortality independent of other organ disorders. The quantity of diarrhea may be a candidate when adjusting for organ dysfunction. Second, diarrhea can be a sign of a disorder of the gut microbiota, which is called dysbiosis. This dysbiosis is believed to increase vulnerability to nosocomial infections, sepsis, organ failure, and mortality $[44,45]$. The development of diarrhea might be associated with dysbiosis in the gut microbiota of ICU patients [46]. However, our data and analyses are not sufficiently conclusive to prove them. Further research is needed to test these hypotheses.

This study had several limitations. First, the measurement of diarrhea was not completely accurate. If diarrhea spills out of the diaper, it may not be measured. In this case, this may have led to an underestimation of the quantity of diarrhea. However, we believe that this measurement of the quantity of diarrhea reflects real clinical practice. Second, the inter-rater reliability of BSCS was not confirmed in our study. The reliability of BSCS has been studied and widely used [26-32], and our nurses were trained to measure BSCS in clinical practice, which should have minimized the inter-rater variability. Third, we did not obtain information on urinary catheter insertion. However, we expect that most patients in this study had urinary catheters because only critically ill patients were admitted to our ICU (a median SOFA score of 9 and $63.6 \%$ of them were on ventilators). Finally, this was a single-center study, and the generalizability of the results is limited.

\section{Conclusions}


In ICU patients with newly developed diarrhea, greater quantity of diarrhea was associated with higher mortality. The quantity of diarrhea may be considered an indicator of disease severity in ICU patients. Further research is needed to determine if there is a causal relationship between the quantity of diarrhea and death.

\section{Abbreviations}

ICU

Intensive care unit

RR

Risk ratio

IQR

Interquartile range

$\mathrm{Cl}$

Confidence interval

ESICM

European Society of Intensive Care Medicine

CDI

Clostridium difficile infection

CMV

Cytomegalovirus

STROBE

Strengthening the Reporting of Observational studies in Epidemiology

WHO

World Health Organization

BSCS

Bristol stool chart scale

$\mathrm{CCl}$

Charlson Comorbidity Index

APACHE

Acute Physiology and Chronic Health Evaluation

SAPS

Simplified Acute Physiology Score

SOFA

Sequential Organ Failure Assessment

\section{Declarations}

\section{Ethics approval and consent to participate}


This study was approved, and the need for informed consent was waived by the institutional review boards of the participating hospital.

\section{Consent for publication}

Not applicable.

\section{Availability of data and materials}

The dataset of this study is not publicly available based on the decision of the first author.

\section{Competing interests}

All authors have no conflicts of interest to declare.

\section{Funding}

This study did not receive any specific grant from funding agencies in the public, commercial, or not-forprofit sectors.

\section{Authors' contributions}

RY has complete access to the study data and takes responsibility for the data integrity. All authors contributed to the study concept and design. RY and YU contributed to data acquisition. RY and RU contributed to data analysis and interpretation. RY, RU, and HY drafted the manuscript. All authors are responsible for the critical revision of the manuscript for important intellectual content and have approved the final manuscript.

\section{Acknowledgments}

The authors thank the staff of the ICU of the Kameda Medical Center. We thank the Japanese Society of Education for Physicians and Trainees in the Intensive Care Clinical Trial Group for their suggestions and comments on the earlier concept of this study.

\section{References}

1. Reintam Blaser A, Deane AM, Fruhwald S. Diarrhoea in the critically ill. Curr Opin Crit Care. 2015;21(2):142-53.

2. Thibault R, Graf S, Clerc A, Delieuvin N, Heidegger C, Pichard C. Diarrhoea in the ICU: respective contribution of feeding and antibiotics. Crit Care. 2013;17(4):R153.

3. Reintam Blaser A, Malbrain MLNG, Starkopf J, Fruhwald S, Jakob SM, De Waele J, et al. Gastrointestinal function in intensive care patients: terminology, definitions and management. Recommendations of the ESICM Working Group on Abdominal Problems. Intensive Care Med. 2012;38(3):384-94. 
4. Reintam A, Parm P, Kitus R, Kern H, Starkopf J. Gastrointestinal symptoms in intensive care patients. Acta Anaesthesiol Scand. 2009;53(3):318-24.

5. Hiesmayr M, Schindler K, Pernicka E, Schuh C, Schoeniger-Hekele A, Bauer P, et al. Decreased food intake is a risk factor for mortality in hospitalised patients: the NutritionDay survey 2006. Clin Nutr. 2009;28(5):484-91.

6. Borges SL, Pinheiro BDV, Pace FHDL, Chebli JMF. Diarréia nosocomial em unidade de terapia intensiva: incidência e fatores de risco. Arq Gastroenterol. 2008;45(2):117-23.

7. Ozgur M, Girgin NK, Akalin H, Iscimen R, Sinirtas M, Kahveci F. A retrospective evaluation of the incidence and risk factors of nosocomial diarrhea in critically ill adult patients. Acta Medica. 2016;32:741-6.

8. Tirlapur N, Puthucheary ZA, Cooper JA, Sanders J, Coen PG, Moonesinghe SR, et al. Diarrhoea in the critically ill is common, associated with poor outcome and rarely due to Clostridium difficile. Sci Rep. 2016;6(1):24691.

9. Wu TJ, Liu ZJ, Zhao YM, Yang CL, Zhang CY. [Clinical analysis of the factors related to diarrhea in intensive care unit]. Zhongguo Wei Zhong Bing Ji Jiu Yi Xue. 2004;16(12):747-9.

10. Jakob SM, Bütikofer L, Berger D, Coslovsky M, Takala J. A randomized controlled pilot study to evaluate the effect of an enteral formulation designed to improve gastrointestinal tolerance in the critically ill patient-the SPIRIT trial. Critical Care. 2017;21(1).

11. Vieira LV, Pedrosa LAC, Souza VS, Paula CA, Rocha R. Incidence of diarrhea and associated risk factors in patients with traumatic brain injury and enteral nutrition. Metab Brain Dis. 2018;33(5):1755-60.

12. Rodrigues de Barros J, Fraga Lobo IM, Melo Soares F, Ferreira de Almeida DSS. Factors associated with diarrhea in a unit of intensive therapy: cohort study. NUTRICION CLINICA Y DIETETICA HOSPITALARIA. 2018;38(2):122-7.

13. Atasever AG, Ozcan PE, Kasali K, Abdullah T, Orhun G, Senturk E. The frequency, risk factors, and complications of gastrointestinal dysfunction during enteral nutrition in critically ill patients. Ther Clin Risk Manag. 2018;14:385-91.

14. Taito S, Kawai Y, Liu K, Ariie T, Tsujimoto Y, Banno M, et al. Diarrhea and patient outcomes in the intensive care unit: Systematic review and meta-analysis. J Crit Care. 2019;53:142-8.

15. Altman DG, Royston P. The cost of dichotomising continuous variables. BMJ. 2006;332(7549):1080.1.

16. Dawson NV, Weiss R. Dichotomizing Continuous Variables in Statistical Analysis. Med Decis Making. 2012;32(2):225-6.

17. Wierdsma NJ, Peters JH, Weijs PJ, Keur MB, Girbes AR, Van Bodegraven AA, et al. Malabsorption and nutritional balance in the ICU: fecal weight as a biomarker: a prospective observational pilot study. Crit Care. 2011;15(6):R264.

18. Anigilaje EA. Management of Diarrhoeal Dehydration in Childhood: A Review for Clinicians in Developing Countries. Front Pediatr. 2018;6:28. 
19. Von Elm E, Altman DG, Egger M, Pocock SJ, Gøtzsche PC, Vandenbroucke JP. The Strengthening the Reporting of Observational Studies in Epidemiology (STROBE) Statement: Guidelines for Reporting Observational Studies. Ann Intern Med. 2007;147(8):573.

20. Diarrhoeal disease 2017 [updated 2. May 2017. Available from: https://www.who.int/en/newsroom/fact-sheets/detail/diarrhoeal-disease.

21. Seymour CW, Liu VX, Iwashyna TJ, Brunkhorst FM, Rea TD, Scherag A, et al. Assessment of Clinical Criteria for Sepsis. JAMA. 2016;315(8):762.

22. Charlson ME, Pompei P, Ales KL, MacKenzie CR. A new method of classifying prognostic comorbidity in longitudinal studies: development and validation. J Chronic Dis. 1987;40(5):373-83.

23. Knaus WA, Draper EA, Wagner DP, Zimmerman JE. APACHE II: a severity of disease classification system. Crit Care Med. 1985;13(10):818-29.

24. Le Gall JR, Lemeshow S, Saulnier F. A new Simplified Acute Physiology Score (SAPS II) based on a European/North American multicenter study. Jama. 1993;270(24):2957-63.

25. Vincent JL, Moreno R, Takala J, Willatts S, De Mendonça A, Bruining H, et al. The SOFA (Sepsisrelated Organ Failure Assessment) score to describe organ dysfunction/failure. On behalf of the Working Group on Sepsis-Related Problems of the European Society of Intensive Care Medicine. Intensive Care Med. 1996;22(7):707-10.

26. O'Donnell LJ, Virjee J, Heaton KW. Detection of pseudodiarrhoea by simple clinical assessment of intestinal transit rate. BMJ. 1990;300(6722):439-40.

27. Lacy BE, Mearin F, Chang L, Chey WD, Lembo AJ, Simren M, et al. Bowel Disorders Gastroenterology. 2016;150(6):1393 - 407.e5.

28. Cook DJ, Johnstone J, Marshall JC, Lauzier F, Thabane L, Mehta S, et al. Probiotics: Prevention of Severe Pneumonia and Endotracheal Colonization Trial-PROSPECT: a pilot trial. Trials. 2016;17(1).

29. Koh H, Lee MJ, Kim MJ, Shin JI, Chung KS. Simple diagnostic approach to childhood fecal retention using the Leech score and Bristol stool form scale in medical practice. J Gastroenterol Hepatol. 2010;25(2):334-8.

30. Dionne JC, Sullivan K, Mbuagbaw L, Takaoka A, Duan EH, Alhazzani W, et al. Diarrhoea: interventions, consequences and epidemiology in the intensive care unit (DICE-ICU): a protocol for a prospective multicentre cohort study. BMJ Open. 2019;9(6):e028237.

31. Caroff DA, Edelstein PH, Hamilton K, Pegues DA. The Bristol Stool Scale and Its Relationship to Clostridium difficile Infection. J Clin Microbiol. 2014;52(9):3437-9.

32. Lewis SJ, Heaton KW. Stool Form Scale as a Useful Guide to Intestinal Transit Time. Scand J Gastroenterol. 1997;32(9):920-4.

33. Bishop S, Young H, Goldsmith D, Buldock D, Chin M, Bellomo R. Bowel motions in critically ill patients: a pilot observational study. Crit Care Resusc. 2010;12(3):182-5.

34. Schmidt SB, Kulig W, Winter R, Vasold AS, Knoll AE, Rollnik JD. The effect of a natural food based tube feeding in minimizing diarrhea in critically ill neurological patients. Clin Nutr. 2019;38(1):332- 
40.

35. Agus MSD, Wypij D, Hirshberg EL, Srinivasan V, Faustino EV, Luckett PM, et al. Tight Glycemic Control in Critically III Children. N Engl J Med. 2017;376(8):729-41.

36. Self WH, Semler MW, Wanderer JP, Wang L, Byrne DW, Collins SP, et al. Balanced Crystalloids versus Saline in Noncritically III Adults. N Engl J Med. 2018;378(9):819-28.

37. Zou G. A Modified Poisson Regression Approach to Prospective Studies with Binary Data. Am J Epidemiol. 2004;159(7):702-6.

38. Holmberg MJ, Andersen LW. Estimating Risk Ratios and Risk Differences. JAMA. 2020;324(11):1098.

39. Rubin DB. Multiple imputation for nonresponse in surveys. John Wiley \& Sons; 2004.

40. Groothuis-Oudshoorn K, Van Buuren S. Mice: multivariate imputation by chained equations in R. J Stat Softw. 2011;45(3):1-67.

41. Wasserstein RL, Lazar NA. The ASA Statement on p-Values: Context, Process, and Purpose. The American Statistician. 2016;70(2):129-33.

42. Lebak KJ, Bliss DZ, Savik K, Patten-Marsh KM. What's New on Defining Diarrhea in Tube-Feeding Studies? Clinical Nursing Research. 2003;12(2):174-204.

43. Reintam Blaser A, Poeze M, Malbrain MLNG, Björck M, Oudemans-Van Straaten HM, Starkopf J. Gastrointestinal symptoms during the first week of intensive care are associated with poor outcome: a prospective multicentre study. Intensive Care Med. 2013;39(5):899-909.

44. Kitsios GD, Morowitz MJ, Dickson RP, Huffnagle GB, McVerry BJ, Morris A. Dysbiosis in the intensive care unit: Microbiome science coming to the bedside. J Crit Care. 2017;38:84-91.

45. Mcdonald D, Ackermann G, Khailova L, Baird C, Heyland D, Kozar R, et al. Extreme Dysbiosis of the Microbiome in Critical Illness mSphere. 2016;1(4):e00199-16.

46. Duan J, Meng X, Liu S, Zhou P, Zeng C, Fu C, et al. Gut Microbiota Composition Associated With Clostridium difficile-Positive Diarrhea and C. difficile Type in ICU Patients. Frontiers in Cellular and Infection Microbiology. 2020;10.

\section{Figures}




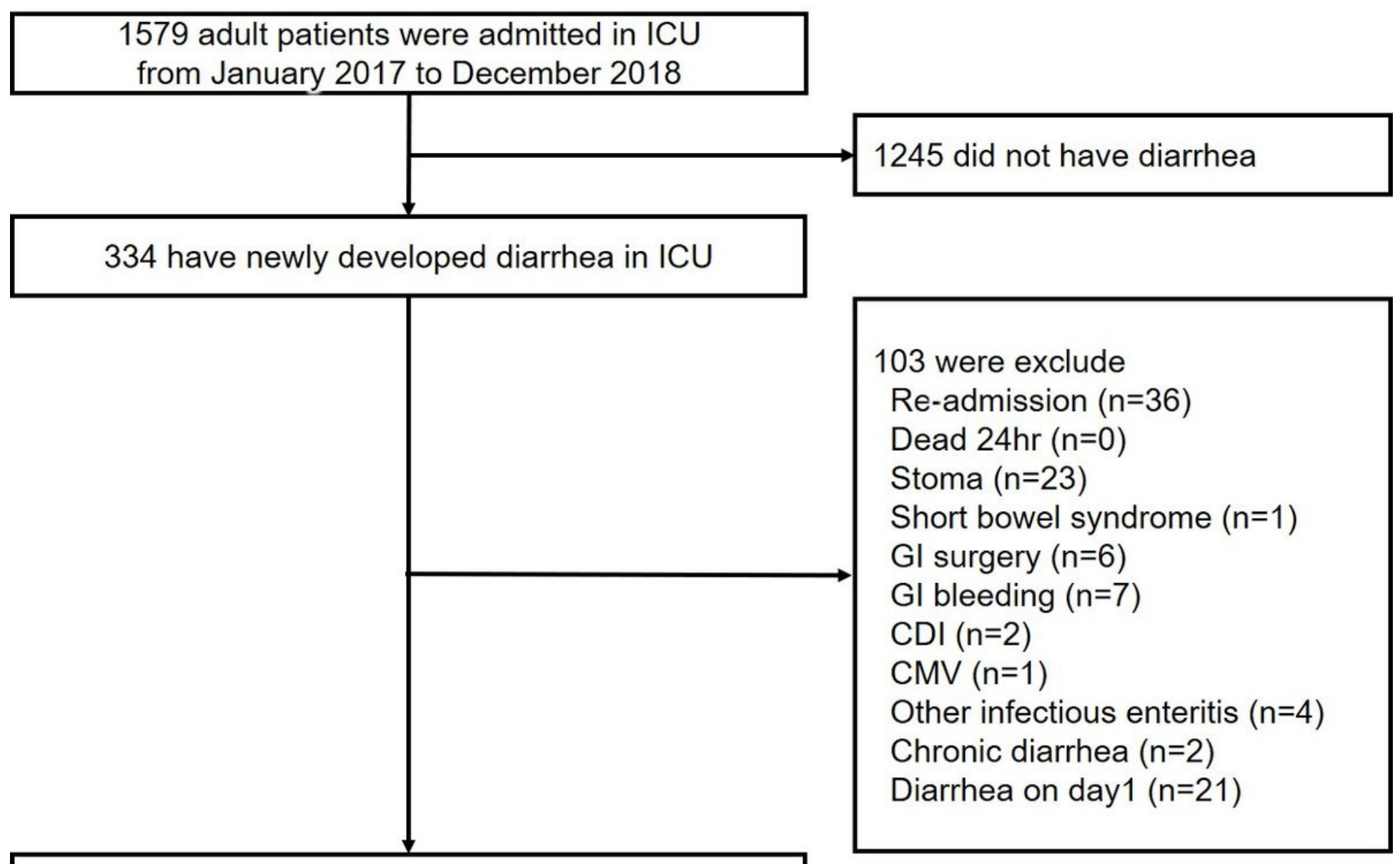

231 were analyzed

Figure 1

Flow diagram 